\title{
Engaging a Community-based Perspective: The Problems of and Prospects for a Grassroots Endeavor in the Dominican Republic
}

\section{Karie Peralta and John Murphy}

University of Miami

\begin{abstract}
The purpose of this article is to bring to the forefront the inconsistency of so-called "grassroots" organizations that operate by using traditional structures. The case of Educate Everyone, a nonprofit organization in the Dominican Republic, is utilized to illustrate this incompatibility at the organizational level, and identify the ways in which this issue plays out in a project. Additionally, possibilities for the organization to employ a community-based framework are discussed. The accounts that are presented to explore the central theme stem from two months of fieldwork that were spent carrying out a participatory action research project with volunteers who support Educate Everyone's annual academic camp.
\end{abstract}

Keywords: community-based, grassroots, organizations, education, participatory action research

\section{Introduction}

This article focuses on how traditional organizations are incompatible with a community-based philosophy (Murphy, 2014). The purpose is to bring to the forefront the inconsistency of socalled "grassroots" organizations that operate using bureaucratic structures. In order to meet this aim, the case of Educate Everyone ${ }^{1}$, a non-profit organization in the Dominican Republic, is explored. The first section articulates a community-based perspective that is important for examining if organizations and projects are integrated into a community, and outlines the differences between traditional and community-based organizational frameworks. The second describes Educate Everyone, how this organization reflects a traditional design, and how the bureaucratic elements of Educate Everyone are reproduced in its educational projects. The third section highlights additional possibilities for Educate Everyone's project, given particular organizational changes. And the fourth section recognizes participation as a key element for organizations that strive for social change.

1 "Educate Everyone" is a pseudonym that is used for confidentiality purposes. 
The approach taken in this work entails providing accounts of a wider research initiative, which included two months of fieldwork that were spent carrying out a participatory action research project (Fals Borda, 1988; McIntyre, 2008) with the volunteers who support Educate Everyone's annual academic camp. The purpose of this research was to assess the prospects for improving volunteer participation and collaboration in this program. The central theme of this article, however, developed subsequent to reflection on the information gathered from participantobservation, organizational documents, five discussion groups of 14-27 participants, three focus groups of 5-6 participants, and 30 interviews with volunteers and organizational staff.

Many community-based endeavors, such as Educate Everyone, are applauded but often evade critique. Nonetheless, self-declared "grassroots" organizations may need to make significant changes in order to reflect a community-based orientation (Murphy, 2014). The problem is that many of these organizations are not equipped with the theoretical insight to recognize when and how they lose this sense of direction. Equally important, they lack a strategy that aligns their projects with this philosophy.

\section{Organizations from a Community-based Perspective}

A community-based perspective (Murphy, 2014) breaks from the traditional view of social existence and organizational life, and instead, is comparable with the outlook of critical community practice that emphasizes solidarity and social inclusion (Kagan and Burton 2001). Order and knowledge, in particular, are not grounded on an autonomous and absolute foundation, as proposed by mainstream sociologists, but are co-constructed through human coordination, as a result of persons inventing themselves based on their interpretations of situations and actions (Blumer, 1969). Accordingly, a community and its development are shaped collectively via the interactions of persons and their understandings of themselves and others. In short, a community-based perspective recognizes that a community is socially constructed (Day, 2006). Persons who participate in this creation are responsible for giving the community and its needs meaning (Murphy, 2014). Therefore, those who desire to utilize this view to understand community-based organizations and their projects should not rely on a dualistic approach that ignores the intimate connection between human action and knowledge (Harris, 2010). In fact, local knowledge and in-put is useful in every facet of a community-based initiative.

\section{Traditional versus Community-based Organizational Frameworks}

This section focuses on three core concepts that serve as points to compare traditional and community-based organizations: hierarchical design, division of labor, and expert knowledge base. These organizational features are standard for traditional organizations, but must be transformed for community-based endeavors. Conventional understandings of organizational management reflect the philosophy of realists (Reed, 2009), while more critical views are informed by social constructionism (Thompson \& O'Doherty, 2009). Founded on a hierarchical design, traditional organizations are formed by positions that are established according to expertise and experience (Weber, 1968). Authority is centralized at the top of the hierarchy in the hands of supervisors and managers, who draw from their specialized knowledge for directing and planning purposes. Accordingly, lower ranked members execute the work that they have been delegated in the prescribed manner. In this way, a division of labor is created that locks members into their assigned roles (Lune, 2010). Although this structure may produce 
accountability (Child, 2009), the average member is provided minimal flexibility in carrying out daily tasks, little opportunity for creative work, and marginal involvement in goal development. Such arrangements have bureaucratic norms and are assumed to be efficient, which makes this model appealing (Purser \& Cabana, 1998).

Opposed to this view of organizations, a community-based strategy requires active member participation and democratic engagement in all activities. Decision-making power and expert knowledge is distributed (Locke, 2003), so that there is a collective approach to authority (Rothschild-Whitt, 1979). Although this feature may seem ideal, dominant leaders may be needed to facilitate this change in management (Fletcher \& Käufer, 2003), while accountability may be weak (Green \& Matthias, 1997). Nevertheless, a participatory scheme encourages shared leadership, pooled resources, and joint efforts to ensure that members learn the skills essential for success (Ramnarayan, 2011b). Along these lines, a grassroots initiative corresponds to existing needs that are identified by the community (Fals Borda, 1988) and is sustained by community support (Murphy, 2012).

Because of this emphasis on "decentralization" (Ramnarayan, 2011a), persons who come to see themselves as part of a community at any given time can contribute to the organization. Tasks can be identified and undertaken by any individual, or any combination of individuals, with interest, and not just by those with certain credentials (Raelin, 2003). The assumption is that skills can be taught and learned by all involved, since leadership is not an intrinsic characteristic (Van Wart, 2003).

Since most community-based organizations are small, this shift in leadership style should not be problematic. In larger organizations, however, there is debate over the viability of a horizontal model of organization life (Fletcher \& Käufer, 2003). Particularly important is whether shared leadership results in effective decision-making (Locke, 2003), and all persons can emerge as leaders among a group of assertive and influential individuals (Seers, Keller, \& Wilkerson, 2003).

In sum, on the one hand, a community-based perspective recognizes that traditional organizations discount human agency and distrust "people's power" (Fals Borda, 1988, p. 2). On the other hand, participatory designs focus on the taken-for-granted practices that challenge hegemony (Fournier \& Grey, 2000). In these ways, a community-based perspective is aligned with an intellectual movement that emphasizes participation and democracy. Accordingly, specific guidelines never dominate organizational life, and varying ideals and objectives are viewed as equally important (Alvesson, 1985).

\section{Educate Everyone:}

\section{A Traditional Organization with a Community-Based Purpose}

Organizational documents and interviews with staff members portray Educate Everyone as a community-based organization. The bureaucratic model that was observed, however, is problematic for accomplishing grassroots work. The purpose of this section is to elaborate on this incompatibility at the organizational level.

Contrary to a community-based framework that recommends a "flat" model (Chetkovich \& Kunreuther, 2006; Murphy, 2014), Educate Everyone has a hierarchical arrangement that is 
reflected in a traditional organizational chart (Sternberg \& Heil, 2000), with the board of directors and executive director at the head of the organization. Further down the line of command are managers, who supervise the offices, and program administrators, who coordinate the teaching staff, volunteers, and maintenance workers. Such a division of labor ensures the stability of work arrangements (Lune, 2010) and minimizes confusion and inefficiency (Whyte et al., 2003).

Being innovative, within this structure, appears to be part of the daily experience of superiors. This observation is not to suggest that Educate Everyone prohibits the creativity of those in lower-level positions. In fact, one low-level staff member was observed designing and implementing a new program of his own creation. However, such ideas are subject to approval by senior staff members. Participation is thus controlled to the extent that behaviors must comply with the demands of authority figures, thereby possibly obscuring the insights of staff members (Whyte et al., 2003).

From a community-based and critical community practice perspective, constrained participation is a major downfall of the traditional organizational structure and an obstacle for realizing community change (Bess et al., 2009). In grassroots organizations, all persons are encouraged to contribute their ideas (Chetkovich \& Kunreuther, 2006). Specifically, all persons can use their creative ability to support, as well as guide, activities by reflecting on and taking appropriate actions that are deemed acceptable to the group. In this sense, open participation is never considered to be a potential hindrance to progress, but rather is central for accomplishing organizational goals.

In Educate Everyone, each organizational position is outlined by a job description, and thus the assigned duties may delimit participation. For example, the executive director and other administrators are designated leaders of different educational projects. Consequently, they are responsible for managing resources and personnel needed to run these programs. In effect, they are the primary decision-makers in how projects are to be carried out. Such a division of labor can easily begin to reduce motivation and stifle creativity.

Additionally, a gap exists between bureaucracies and communities, due to the issue of boundary maintenance (Manning, 1982). This condition places Educate Everyone in a weak position to pursue endeavors that are truly meaningful to community members. After all, grassroots efforts stem from the members of a community (Groch et al., 2012; Kaye, 2001), rather than from the ideas of a few individuals who occupy positions at the top of an organization. Nevertheless, due to the preoccupation with a stable order, bureaucracies must remain separate from the contingencies that are associated with communities.

To illustrate this point, Educate Everyone relies generally on persons with professional training to gather and analyze the data that are used to design and monitor projects. These procedures are intended to guarantee that the information that is collected is objective, and therefore can be used to plan interventions (Davies, 1999). Allowing the average community member, or minimally trained staff person, to participate in this aspect of organizational development runs the risk of information being tainted by personal experience.

Although staff members of Educate Everyone were observed soliciting testimonies and feedback in evaluations that could serve as information for program development, organizational 
documents describe interventions as being based on evidence and potential impact (Davies, 1999). Such an approach may not be attuned to how the reality of the program participants is constructed (Murphy, 2014), thereby impeding the processes of "cultural grounding" (PalmerWackerly et al., 2014) that may otherwise facilitate the active involvement of a community in creating locally relevant programs (Colby et al., 2013).

\section{Organizational Issues Reproduced in a Project}

The bureaucratic nature of Educate Everyone has implications for endeavors intended to be community-based. This section employs a community-based perspective to understand some of the problems that occurred during the course of a project. Specific attention is given to issues related to the reproduction of a hierarchical model, division of labor, and expert knowledge in the organization.

\section{The Academic Camp}

For over a decade, Educate Everyone has incorporated local and international volunteers into education and community development projects that target disadvantaged populations, similar to many organizations in developing countries (Green \& Matthias, 1997). Each year, this organization operates summer academic camps in semi-rural, poor areas. The aim of these programs is to advance math, literacy, and life skills of youth at-risk of dropping out of school, and to train local teachers instructional techniques that they could apply during the school year with the guidance of "expert" education volunteers.

This past summer over 400 children participated in the camp in three different sites. More than 60 volunteers carried out activities. This community of volunteers is the focus of the subsequent discussions. Specifically, there were 45 local and 16 international volunteers who became teacher trainers, teachers, or counselors. The local volunteers included 29 teachers and 16 counselors, while the international volunteers consisted of five trainers and 11 counselors.

Each volunteer position required certain qualifications and was attributed corresponding responsibilities. The trainers were teachers in the United States. They were responsible for training local teachers and ensuring the successful implementation of literacy techniques in the classroom. Most of the teachers were employed by local public schools or were studying to be educators. They applied to teach the core curriculum, such as math and reading, during the camp with the incentive of learning new pedagogical strategies. The teachers who guided the life skills component of the program were trained facilitators. The counselors were persons who had experience working with children, but not necessarily in a teaching capacity. While trainers and teachers worked together to provide instruction, all counselors were responsible for managing discipline and supporting the learning experience. Volunteers worked in classroom teams that were comprised of one teacher trainer, two local teachers, and two to three camp counselors. Most teams included at least one local and one international counselor. For the most part, these teams remained stable throughout the camp.

For classroom management purposes, and to increase attention given to the camp participants, the teams often implemented activities that utilized "stations" (Teacher Quality Enhancement Center, 2009). Although this strategy is common in the American context, the concept of stations as a teaching tool is a fairly new for Dominican teachers. This approach involved 
participants working in small groups on specific activities, usually guided by a volunteer, and rotating stations every 10 to 15 minutes.

\section{The Hierarchical Structure of the Camp}

A hierarchy, similar to that of the organization, established the structure of the camp. Although the executive director controlled the funding of the project, and provided general guidance, the academic director was observed to have more authority over planning. She approved the curriculum, accepted local teachers into the program, and led training workshops. At these trainings, teachers were observed being asked to share their ideas. In a word, teachers were not treated as if they were completely passive. However, they did not have a hand in guiding a program. Instead, they were seen as simply going along with the ways in which the organization designed activities and rarely offered critique. In fact, at first, not one local teacher questioned the implementation of stations as a viable teaching technique.

However, later in the camp, one of the teachers disclosed to the lead author that stations would be less practical in a typical public school classroom. Her point was that using small group activities with a class of approximately 20 students and four adult facilitators, including two teachers and two counselors, was not expected to work in the same way in a classroom of 40 students and a single instructor. In other words, their lived experience suggested that stations, a technique that was intended to be useful for teachers during the regular academic year, would not work well in the average classroom.

This example may be considered representative of how hierarchical relations contribute to the persistence of power imbalance (Child, 2009) and practices that become hegemonic, which have been a concern for critical education theorists (McLaren \& Giroux, 1997). Communitybased philosophy (Murphy, 2014) provides the logic behind why instructional models do not necessarily have to be generalizable. The point is that initiatives should be aligned specifically with a community's "biography" (Berger \& Luckmann, 1966), which is comprised of the blended interests and values of community members. Although grassroots projects may be open to trying out methods that are imported from other contexts, a community-based approach maintains a critical view of development processes, including the community engagement that is necessary to ensure that such practices are not imposed, and, if implemented, are effective (Ozer et al., 2013).

Along these lines, counselors also recognized when plans were not feasible given their situation, but they did little to make their concerns known. For example, counselors were observed being encouraged to collaborate with one another to develop community projects. This idea came from two of the directors who created their own projects when they were counselors in previous years. They believed that this opportunity would foster professionalism. Additionally, involvement in the projects was anticipated to increase their contribution, motivation, crosscultural collaboration, and satisfaction, thereby encouraging "buy-in" (Woods, 2013) to the program. The objective was for counselors to identify a project that would address a community need, and allow them to utilize and develop their skills. Similar approaches that allow participants to put into action their own ideas have been intended to create empowering environments (Blythe et al., 2013). 
Although the possibility for creating these projects was not met with resistance at first, several international counselors began to view successful completion of a project as unrealistic and discussed this issue during a focus group. Particularly, they exerted much of their energy on learning and performing their responsibilities for the camp. These international volunteers recognized that the adjustment period that they needed with respect to learning a new language and culture, and being away from family and friends, made concentrating on projects difficult. However, their main concern was the lack of time during the day to develop ideas.

The problem is that counselors who felt this way were reluctant to discuss these challenges with the camp directors. Even though completing a project was not formally required, some international counselors sensed that they were expected to develop a sound proposal. They thought that the directors would view them as undedicated if they did not participate, and therefore did not raise concerns. As a result, there was no discussion between counselors and directors that could have informed solutions. In this way, the authority structure may have impeded communication that could have been useful for overcoming barriers to project elaboration, because counselors felt compelled to accept ideas proposed by the directors.

\section{An Emphasis on Roles}

Since roles were important in the organizational setting, they were also specified for volunteers at the outset of the camp during an orientation workshop. For example, counselors were expected to support classroom instruction but not teach. The purpose of this distinction was to avoid confusion and frustration that occurred in past years. In a planning meeting, directors discussed the importance of counselors keeping to their roles, so that the camp may operate smoothly.

The issue with roles, however, is that they confine participation in ways that do not always contribute to success. This problem became apparent while observing counselors leading station activities. Several international and local counselors confirmed this view during a discussion group. Given the design of this instructional method, counselors were put in the position to teach. Often counselors struggled with the situation; they knew that teaching was not part of their role-in a bureaucracy a strict division of labor is the norm.

During training, all counselors had been made aware of how they could help in the classroom, for example, by organizing materials and providing discipline. Nevertheless, some international counselors recognized that they would have to learn some instructional techniques if they were going to contribute to camp success. In fact, they expressed in interviews and discussion groups how they relied on their own observations to learn different approaches to teaching. Some of these counselors asked the teachers and trainers to share their knowledge regarding appropriate strategies. In the end, teaching became a shared responsibility of the entire classroom team, which is how many teachers viewed this task in the first place.

\section{Experts in the Project}

Similar to how skill mastery influences organizational practices, expertise is often a key factor in project development. However, a community-based perspective helps to identify when "local knowledge" (Fals Borda, 1988) is being overlooked, and, moreover, provides a lens for understanding how expert knowledge usually is not a springboard for initiatives. From a 
grassroots viewpoint, new insights can be gained into aspects of projects that were taken for granted previously.

A common concern for most organizations is securing financial resources for projects. Generally, new funding allows Educate Everyone to seek out prospective areas to construct schools and implement programs. Although funding opens possibilities, a problematic issue is that projects often begin with a donor rather than a community, and thus pleasing the funder becomes a main priority. As a result, local knowledge is discounted as valuable for the foundation and future of community-based initiatives, and thus no attempt is made to understand how the project fits into the reality of the community (Murphy, 2014).

Regarding the academic camp, organizational materials related to recruitment portrayed the teacher trainers to be the teaching experts. All trainers were required to have a teaching certification, three years of classroom experience, and fluency in Spanish. Therefore, these qualifications were associated with expertise. And so, the trainers guided training and often planned classroom activities. However, some local teachers had Masters' degrees and numerous years of teaching experience, as well as cultural familiarity, but were not considered educational experts. When there are status differentials and a strict division of labor, this sort of irrationality often is discovered.

\section{The Possibilities of a Community-Based Project}

Perhaps the most promising benefit of utilizing a community-based perspective is that new possibilities for projects are revealed. Moreover, these prospects are enhanced by being intimately connected to the reality of the community. The following possibilities at Educate Everyone's academic camp were discovered by members of the volunteer community over the course of the participatory action research project (Fals Borda, 1988; McIntyre, 2008), and made known to the organization in the form of a written and oral report by the lead author. Had the opportunity to participate in the dissemination process, including the writing of this article, been open to community members, the project would have reached a primary goal of the participatory approach (Israel et al., 2003). The authors thus recognize this shortcoming, which is due primarily to logistical constraints and how the present theme was not an original focus but became apparent as an issue worth highlighting after fieldwork was completed.

The first possibility relates to the integration of volunteers into a project. Although volunteers may have different motives, such as the desire to help others or gain career-related experience (Musick \& Wilson, 2008), a community-based perspective does not consider this aspect to be problematic with respect to completing a project. In fact, the talents and skills of volunteers, despite distinctions among their intentions, values, and backgrounds, can be interwoven in ways that contribute to communally approved objectives. During interviews, both local teachers and volunteers confirmed the worth of international participants, because they contribute new skills and energy to projects. Yet, the coordination and association of all these volunteers with the local community is crucial.

One of the main concerns that was identified during discussion groups and interviews with several international and local volunteers was that classroom teams lacked cooperation and communication. Most participants noted that teams needed time to build relationships, get organized, and discuss classroom management approaches. Therefore, they proposed that the 
schedule allot time for team members to become familiar with one another's strengths and abilities, and decide how they will work together. Furthermore, they believed that this opportunity could be utilized by teachers to share their knowledge with counselors regarding teaching techniques.

This remedy for collaboration elevates information exchange and skill development in importance, which may contribute to a collective knowledge base that may be used to enhance organizational capacity (Gill, 2010). Along these lines, the fact that the camp is designed to include substantial teamwork, the project already has a blueprint in place for self-management (Purser \& Cabana, 1998). After closer examination, all volunteers often rotated positions during activities, which from a community-based perspective, facilitates the operation of a participatory model (Chetkovich \& Kunreuther, 2006). Nonetheless, the typical hierarchy of classrooms should be cast aside, if this technique is going to be fully realized.

A second possibility pertains to the professional development of both national and international counselors. As previously mentioned, the directors encouraged counselors to create community projects with the hope that these efforts would result in personal and organizational achievements. In this way, the counselors could experience a sense of fulfillment from their work while advancing organizational goals.

This strategy, however, was observed to be less successful than expected. Nevertheless, during a focus group, international and local participants engaged in conversation about the issues that they encountered, which resulted in the production of a model that is intended to help future volunteers implement a project. This model encourages volunteers to become attuned to the biography (Berger \& Luckmann, 1966) of the community, so that project action plans take into account the various perspectives that community members have of their conditions.

Aside from community projects serving as opportunities for counselors to acquire new skills, a teacher-trainer interviewee revealed how they could help counselors strengthen their abilities. Rather than working only with the local teachers, trainers could also support counselors who are interested in educational professions. For example, trainers could facilitate counselors in taking the lead in developing lesson plans. This image does not portray trainers as concealing their knowledge, but rather imparting their wisdom to others.

In a community-based project, there is no hierarchical management that assigns leaders to activities. With respect to Educate Everyone, the bureaucratic nature of the organization may have played a part in why camp directors were observed rarely relinquishing their right to lead, particularly in orientation workshops. Despite the effort to make training both informative and enjoyable, several international counselors declared during a discussion group that some sessions were misguided. Moreover, they felt that they were not provided with a clear picture of how to participate, which meant training did not fulfill its purpose.

However, based on observations, one of the most educational and interactive sessions was facilitated with the assistance of local counselors. Small groups of international volunteers rotated to themed stations where they engaged in dialogue with local volunteers about the cultural identity of the Dominican Republic. To prepare for the workshop, local counselors decided which items they should exhibit as cultural artifacts, and determined who was responsible for obtaining these objects, while international volunteers assembled questions 
related to the themes to present during the discussion. In the end, this activity offered a glimpse of how volunteers could directly guide key aspects of a project.

Therefore, fostering leadership is a third possibility, particularly among counselors. Volunteers are not often considered to be leaders in traditional organizations. After all, most are not paid and may not be present for the long-term. Yet, a collectivist approach to grassroots work involves participants interacting on an egalitarian basis (Rothschild-Whitt, 1979), which means that any volunteer might take on a leadership position in a project. As a result, the pool of resources and skills expands in a way never imagined.

When considering the various possibilities that are related to volunteer leadership from a community-based viewpoint, the training should promote an exchange of knowledge. However, this preparation should not assume the form of an all-encompassing, one-time training, since community-based projects require that participants be active, flexible learners throughout the duration of an endeavor. Incorporating exchanges on an ongoing basis, whereby persons change roles, would be important in order to stay attuned to the changing needs of a community. In this regard, exchanges are compatible with promoting skill development among participants (Fletcher \& Käufer, 2003).

By embracing the notion of leadership in broader terms, the average participant is no longer viewed as ordinary, nor is the skilled participant seen as special. Rather, all participants are understood to be agents of change, and of equal standing, in a unified pursuit. For this reason, any participant can present an idea and, with the support of the group, implement a plan of action.

At this point, an advantage of community-based leadership must be noted. Specifically, effort does not need to be invested to find leaders, since they may arise freely at any place or time (Seers, Keller, \& Wilkerson, 2003). In fact, due to the democratic, open nature of grassroots initiatives (Fisher, 2005), onlookers may aspire to join in on a particular venture. As a result, new participants may offer novel ideas that enable projects to advance in unexpected but beneficial ways.

\section{Conclusion}

Organizations that focus their efforts on local problems, and involve community members in neighborhood projects, are not necessarily community-based. In fact, any "grassroots" project that adopts a bureaucratic arrangement is incompatible with a community-based organization. Recognizing this inconsistency serves as a point of departure for understanding how work can be carried out, and goals can be achieved, utilizing a community-based orientation.

Although a grassroots approach for organizations and projects is clarified, an important fundamental question remains: How does a community-based perspective contribute to understanding the role of organizations in creating social change? The answer begins and ends with democratic participation. Whether the focus is on social interventions (Cole, 2006), community organizing (Fisher, 2005), or policy advocacy (Mix, 2011), the message is that organizations that encourage persons to participate actively and work together are on the right track to improve their communities. 
Although simple in writing, participation and collaboration may be difficult in practice. However, a community-based outlook opens up possibilities so that change is not overly challenging, nor too far in the future to be meaningful. Overall, when a community-based philosophy is adopted correctly, perspective, experience, and action are interconnected in such a way that real change seems feasible.

\section{Contact information:}

Karie Jo Peralta

Department of Sociology

University of Miami

5202 University Drive

Coral Gables, FL 33146

Email: k.peralta@miami.edu

\section{References}

Alvesson, M. (1985). A critical framework for organizational analysis. Organization Studies, 6(2), 117-138.

Berger, P., \& Luckmann, T. (1966). The social construction of reality: A treatise in the sociology of knowledge. Garden City, NY: Doubleday.

Bess, K., Prilleltensky, I., Perkins, D., \& Collins, L. (2009). Participatory organizational change in community-based health and human services: From tokenism to political engagement. American Journal of Community Psychology, 43(1), 134-148.

Blumer, H. (1969). Symbolic interaction: Perspective and method. Englewood Cliffs, NJ: Prentice-Hall.

Blythe, C., Harré, N., Sharma, S., Dillon, V., Douglas, B., \& Didsbury, A. (2013). Guiding principles for community engagement: Reflections on a school-based sustainability project. Journal for Social Action in Counseling and Psychology, 5(3), 44-69.

Chetkovich, C., \& Kunreuther, F. (2006). From the ground up: Grassroots organizations making social change. Ithaca, NY: Cornell University Press.

Child, J. (2009). Challenging hierarchy. In M. Alvesson, T. Bridgman, \& H. Willmott (Eds.), The Oxford handbook of critical management studies (pp. 501-514). Great Clarendon Street, Oxford: Oxford University Press.

Colby, M., Hecht, M. L., Miller-Day, M., Krieger, J. L., Syvertsen, A. K., Graham, J. W., et al. (2013). Adapting school-base substance use prevention curriculum through cultural grounding: A review and exemplar of adaptation processes for rural schools. American Journal of Community Psychology, 51(1-2), 190-205. 
Cole, C. (2006). Grassroots soccer. Journal of Sport and Social Issues, 30(3), 227-228.

Davies, P. (1999). What is evidence-based education? British Journal of Educational Studies, $47(2), 108-121$.

Day, G. (2006). Community and everyday life. New York, NY: Routledge.

Fals Borda, O. (1988). Knowledge and people's power: Lessons with peasants in Nicaragua, Mexico and Colombia. New York, NY: New Horizons Press.

Fournier, V., \& Grey, C. (2000). At the critical moment: Conditions and prospects for critical management studies. Human Relations, 53(1), 7-32.

Fisher, R. (2005). Social action community organizing: Proliferation, persistence, roots, and prospects. In M. Minkler (Ed.). Community organizing and community building for health $\left(2^{\text {nd }}\right.$ ed.) (pp.51-65). New Brunswick, NJ: Rutgers University Press.

Fletcher J. K., \& Käufer, K. Shared leadership: Paradox and possibility. In C. L. Pearce and J. A. Conger (Eds.). Shared leadership: Reframing the hows and whys of leadership (pp. 21-47). Thousand Oaks, CA: Sage.

Gill, S. J. (2010). Developing a learning culture in nonprofit organizations. Thousand Oaks, CA: SAGE Publications, Inc.

Green, A. \& Matthias, A. (1997). Non-governmental organizations and health in developing countries. New York, NY: Macmillan and St. Martins Press.

Groch, K., Gerdes, K. E., Segal, E. A., \& Groch, M. (2012). The grassroots Londolozi model of African development: Social empathy in action. Journal of Community Practice, 20(1-2), 154-177.

Harris, S. R. (2010). What is constructionism? Boulder, CO: Lynne Rienner Publishers, Inc.

Israel, B. A., Schulz, A. J., Parker E. A., Becker A. B., Allen III, A. J., \& Guzman J. R. (2003). Critical issues in developing and following community based participatory research principles. In M. Minkler \& N. Wallerstein (Eds.), Community Based Participatory Research for Health (pp. 53-76). San Francisco, CA: Jossey-Bass.

Kagan, C., \& Burton, M. (2001). Critical Community Psychology Praxis for the 21st Century. Presented at the British Psychological Society Conference, Glasgow. Retrieved from http://www.compsy.org.uk/GLASGOX5.pdf

Kaye, G. (2001). Grassroots involvement. American Journal of Community Psychology, 29(2), 269-275. 
Locke, E. A. (2003). Leadership: Starting at the top. In C. L. Pearce and J. A. Conger (Eds.). Shared leadership: Reframing the hows and whys of leadership (pp.271-284). Thousand Oaks, CA: Sage.

Lune, H. (2010). Understanding organizations. Malden, MA: Polity Press.

Manning, P. K. (1982). Organizational work: Structuration of environments. British Journal of Social Work, 33(1), 118-134.

1

McIntyre, A. (2008). Participatory action research. Thousand Oaks, CA: Sage Publications.

McLaren, P. \& H. A. Giroux. (1997). Writing from the margins: Geographies of identity, pedagogy, and power. In P. McLaren (Ed.), Revolutionary multiculturalism: Pedagogies of dissent for the new millennium (pp. 16-41). Boulder, CO: Westview Press.

Mix, T. L. (2011). Rally the people: Building local-environmental justice grassroots coalitions and enhancing social capital. Sociological Inquiry, 81(2), 174-194.

Murphy, J. W. (2012). A community-based organization: The Las Mercedes Project. Journal of Social Work in Disability \& Rehabilitation, 11(1): 71-80.

Murphy, J. W. (2014). Community-based interventions: Philosophy and action. New York, NY: Springer.

Musick M. A., \& Wilson, J. (2008). Volunteers: A social profile. Bloomington, IN: Indiana University Press.

Ozer, E. J., Newlan, S., Douglas, L., \& Hubbard, E. (2013). "Bounded" empowerment: Analyzing tensions in the practice of youth-led participatory research in urban public schools. American Journal of Community Psychology, 52(1): 13-26.

Palmer-Wackerly, A. L., Krok, J. L., Dailey, P. M., Kight, L., Krieger, J. L. (2014). Community engagement as a process and an outcome of developing culturally grounded health communication interventions: An example from the DECIDE Project. American Journal of Community Psychology, 53(3-4), 261-274.

Purser, R. E., \& Cabana, S. (1998). The self-managing organization: How leading companies are transforming the work of teams for real impact. New York, NY: The Free Press.

Raelin, J. A. (2003). Creating leaderful organizations: How to bring out leadership in everyone. San Francisco, CA: Berrett-Koehler Publishers, Inc.

Ramnarayan, S. (2011a). Is your organization ready for change? In S. Ramnarayan \& T. V. Rao (Eds), Organization development: Accelerating learning and transformation ( $2^{\text {nd }}$ ed.) (pp. 320-329). Thousand Oaks, CA: Sage. 
Ramnarayan, S. (2011b). Participation: Considerations for designing process. In S. Ramnarayan \& T. V. Rao (Eds), Organization development: Accelerating learning and transformation ( $2^{\text {nd }}$ ed.) (pp. 267-276). Thousand Oaks, CA: Sage.

Reed, M. I. (2009). Critical realism in critical management studies. In M. Alvesson, T. Bridgman, \& H. Willmott (Eds.), The Oxford handbook of critical management studies (pp.52-75). Oxford: Oxford University Press Inc.

Rothschild-Whitt, J. (1979). The collectivist organization: An alternative to rationalbureaucratic models. American Sociological Review, 44(4), 509-527.

Seers, A., Keller, T., \& Wilkerson, J. M. (2003). Can team members share leadership? In C. L. Pearce and J. A. Conger (Eds.). Shared leadership: Reframing the hows and whys of leadership (pp.77-102). Thousand Oaks, CA: Sage.

Sternberg, N., \& Heil, S. (2000). Organization charts: Structures of 230 businesses, government agencies, and non-profit organization ( $3^{\text {rd }}$ ed.). Detroit, MI: Gale Research.

Teacher Quality Enhancement Center. (2009). Co-teaching strategies \& examples [PDF document]. Retrieved from http://www.tacoma.uw.edu/sites/default/files/global/ documents/education/co-teaching_definitions_x_examples.pdf

Thompson, P., \& O'Doherty, D. P. (2009). Perspectives on labor process theory. In M. Alvesson, T. Bridgman, \& H. Willmott (Eds.), The Oxford handbook of critical management studies (pp.99-121). Oxford: Oxford University Press Inc.

Van Wart, M. (2003). Public-sector leadership theory: An assessment. Public Administration Review, 63(2), 214-228.

Weber, M. (1968). Economy and society: An outline of interpretive sociology. G. Roth \& C. Wittich (Eds.). (E. Fischoff, Trans.). New York, NY: Bedminister Press. (Original work published 1924).

Whyte, W. F., Blasi, J. R., \& Kruse, D. L. (2003). Worker ownership, participation and control: Toward a theoretical model. In M. J. Handel (Ed.), The sociology of organizations: Classic, contemporary, and critical readings (pp. 475-501). Thousand Oaks, CA: Sage Publications, Inc.

Woods, K. (2013). Handbook on volunteer management. Retrieved from http://www.ctcconnect.org/images/files/file/Volunteer\%20Handbook\%20For\%20Lumity \%20CTC\%20Partners\%20May-2013\%20B.pdf 